\title{
Forward Momentum: Providing Supportive Space for EdD Students' Dissertation Progression through Weekly Online Writing Sessions
}

\author{
Laura G. Maldonado \\ North Carolina State University \\ lagarlan@ncsu.edu \\ J. Jordan Dolfi \\ North Carolina State University \\ jjdolfi@ncsu.edu \\ James E. Bartlett, II \\ North Carolina State University \\ james_bartlett@ncsu.edu \\ Michelle E. Bartlett \\ North Carolina State University \\ mebartle@ncsu.edu
}

\begin{abstract}
This article describes online writing sessions developed for a CPED Community College Leadership education doctorate EdD program at a research-intensive, land-grant university. Sessions were introduced during the summer of 2020 after the existing executive, face-to-face program shifted entirely to online delivery due to the COVID-19 pandemic. The purpose of the writing sessions was to support students in the EdD, who are practitioners, with dissertation writing productivity by offering multiple weekly opportunities for synchronous writing sessions via online video conferencing. Although this program offering is in early implementation, initial feedback suggests the writing sessions supported students' dissertation progression and established a sense of community and social support in an online environment. This model could benefit online, hybrid, and face-toface $\mathrm{EdD}$ programs in supporting writing progression. Design, delivery, and lessons learned are shared for the benefit of EdD programs as we continue to navigate program delivery impacts from the pandemic.
\end{abstract}

KEYWORDS

online writing sessions, education doctorate, scholarly practitioner, dissertation progress, community building

\section{INTRODUCTION}

Writing is a necessary skill valued by academic, practitioner, and policy audiences (Ferguson, 2009) and a skill scholarly practitioners need to disseminate their work and communicate findings from dissertation research. The education doctorate (EdD) program is one type of Professional Research Doctorate as defined by Colwill (2012) in which coursework is rooted in both practice and practice-based research (Perry \& Abruzzo, 2020). Students in such programs are referred to as scholarly practitioners and often complete a practice-based research dissertation termed dissertation in practice (Perry \& Abruzzo, 2020). There is a growing body of work on writing groups at the doctoral level (Aitchison, 2009, 2010; Ferguson, 2009; Inouye \& McAlpine, 2019, Lassig et al., 2013; Lim et al., 2019; Maher et al., 2013; Wegener et al., 2016). While the majority of this work has focused on doctoral students enrolled in doctor of philosophy $(\mathrm{PhD})$ programs, there is some work on writingrelated services or programs for EdD students (Capello, 2020; Lassig et al., 2013; Murphy et al., 2014). Writing groups help students practice writing skills and develop as scholarly writers (Aitchison, 2009, 2010; Ferguson, 2009; Lassig et al., 2013; Maher et al., 2013; Murphy et al., 2014; Wegener et al., 2016), improve thinking (Aitchison \& Lee, 2006), and build a community of peers (Maher et al., 2013; McAlpine \& Asghar, 2010).

Perry and Abruzzo (2020) wrote that for scholarly practitioners in particular, socialization is a necessary part of graduate programming. In discussing the importance of intentional socialization for EdD students in programs redesigned with influence from the Carnegie Project on the Education Doctorate (CPED) Guiding Principles, Perry and Abruzzo (2020) applied the Weidman models to assert EdD student socialization must take part through
New articles in this journal are licensed under a Creative Commons Attribution 4.0 United States License.

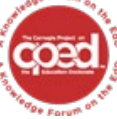

This journal is supported by the Carnegie Project on the Education Doctorate: A Knowledge Forum on the EdD (CPED) cpedinitiative.org 
knowledge acquisition, investment, and involvement. This article focused on socialization via student investment as defined by Weidman et al. (2001) as "time and energy put forth [by the student] in meeting program requirements" (p. 63) and applied by Perry and Abruzzo (2020) to EdD programs as spanning from "applying to the program and ends with completion of the capstone requirement" ( $p$. 138).

This article provides an account of a new program development that could be of broad interest to CPED EdD program educators, specifically, weekly online writing sessions developed in 2020 for students enrolled in a CPED-influenced Community College Leadership (CCL) EdD program at a research-intensive, land-grant university. This newly developed program offering specifically contributes to the investment aspect of EdD student socialization as described by Perry and Abruzzo (2020) in that it offers a new and innovative way to support EdD students' progression through the dissertation and other program-associated writing projects.

This article begins with providing context of the CCL EdD program and background literature on doctoral progression and writing group models. Next, the EdD program and writing session development and delivery is described. Preliminary evaluative feedback about the sessions was gathered from students through a questionnaire and a journal kept by the session facilitator (first author). Finally, lessons learned and considerations for the future are provided.

\section{CONTEXT OF CCL EDD PROGRAM}

The CCL program at North Carolina State University has recently been redesigned to align better with the CPED principles (Bartlett et al., 2018). The EdD program redesign efforts have been supported in part by a grant from a funder to provide resources to enhance the doctoral students' experience. The EdD program in reference is a three-year, cohort-based program geared towards education professionals interested in senior leadership positions in community colleges or workforce development. Students enter the program with work experience as leaders, instructors, faculty, administrators, and accomplished professionals from community colleges, four-year universities, not-for-profit organizations, government, business, and other educational settings. A new cohort of 20-25 students is launched annually, with cohorts alternating distance education locations between two metropolitan areas in the state. Coursework is completed year-round for two years (i.e., summer, fall, spring, summer, fall, spring, summer) in a fixed cohort model of two classes per term. Dissertation hours are integrated throughout the program, beginning in the first fall semester.

The majority of EdD students hold full-time jobs in addition to being doctoral students. Thus, this program is delivered in person every other weekend to maximize accessibility to full-time working professionals who prefer an in-person learning experience to online learning. The program refers to this scheduling as executive format because it is scheduled outside of the typical business day. Classes are scheduled on Fridays from 4 p.m. to 9 p.m. and on Saturdays from 8 a.m. to 5 p.m. However, the program shifted to online delivery in March 2020 due to the COVID-19 pandemic. Keeping in mind the students in this program opted for an in-person program delivery; efforts were made to incorporate new support features to mimic the in-person classroom experience of shared workspace with classmates and the built-in accountability that stems from that experience.

\section{BACKGROUND ON DOCTORAL PROGRESSION AND WRITING GROUPS}

Progressing through a doctoral program is complex and challenging. All students likely begin doctoral programs with the intention of completing their degree. However, around half of the students in the United States who begin a doctoral program do not achieve degree attainment (Okahana \& Zhou, 2019). Muirhead and Blum (2006) wrote that while the doctoral dissertation is an intensely grueling experience for all doctoral students, the task is even more strenuous for online students who do not have the opportunity to work in person with faculty or classmates. Further, high attrition rates continue to plague higher education, as many doctoral students remain all but dissertation ( $A B D$ ) (Muirhead \& Blum, 2006; Page, 2020; Wegener et al., 2016). ABD students are those who finish coursework but are stalled in the dissertation phase, resulting in additional anxiety (Russell-Pinson \& Harris, 2017). With many EdD programs marketing suggested time frames for degree completion, writing groups or sessions are one way to enhance programmatic offerings for writing support without additional cost to the program.

Writing groups can engage students early in the academic process and support them in becoming successful scholars (Aitchison, 2010; Aitchison \& Lee, 2006; Lassig et al., 2013; Maher et al., 2013). Enhanced motivation, increased confidence, and a more positive outlook on the writing process are some of the psychological benefits (Ferguson, 2009). Writing groups can also provide emotional support to those experiencing isolation (Ferguson, 2009). It is common for graduate students to face isolation, and individuals may experience feelings of loneliness, anxiety, and fear when writing by oneself (Lee \& Boud, 2003). Additionally, there are more isolation challenges inherent to online educational programs as students are not able to see each other in person (RockinsonSzapkiw et al., 2016). Given the current COVID-19 pandemic, these feelings may be further exacerbated. Writing together provides an opportunity for engagement in an EdD program to help students build community and avoid feelings of isolation.

Although writing may be thought of as solitary activity, it is often a communal activity (Lassig et al., 2013; Lee \& Boud, 2003). Students enrolled in EdD programs often have limited time for engagement and community building between their work and family commitments with partners, children, or parents (D'Andrea, 2002). EdD scholarly practitioners also bring significant professional experience from the workforce and tend to work full time in educational, government, not-for-profit, and other organizational settings while pursuing their degree (Perry \& Abruzzo, 2020). Establishing a social network is crucial to completing a dissertation (Lim et al., 2019).

\section{Supporting EdD Doctoral Students}

CPED-influenced EdD programs are redesigned using the CPED Framework, which consists of six Guiding Principles and seven Program Design Concepts (The Carnegie Project on the Education Doctorate [CPED], n.d.). One program design concept of CPED EdD programs is, "Scholarly Practitioners blend practical wisdom with professional skills and knowledge to name, frame, and 
solve problems of practice" (CPED, n.d., "Scholarly Practitioner"). Perry and Abruzzo (2020) wrote:

The CPED consortium contends that the transformation of the field lies in the impact of the graduates applying their newly acquired skills and knowledge. Impact on practice comes not only from their leadership abilities newly infused with innovative, scholarly thinking, but also from the work they generate through their dissertation in practice-a scholarly endeavor that impacts a complex problem of practice. (p. 135)

Demonstration of this achievement is through successful completion of a dissertation in practice-scholarly work that impacts a current problem of practice in the field (Perry \& Abruzzo, 2020). In the EdD program in reference, dissertation work starts in the first fall term and is integrated throughout the program. It is important for students to keep moving through coursework to candidacy to dissertation completion in three years. Even with the incorporation of dissertation hours throughout the program, completing this large, independent project is often a challenge as doctoral students transition from a consumer of knowledge to a contributor of research (McPherson et al., 2018; Page, 2020). To face this challenge, it was observed that EdD students in the program in reference organically developed face-to-face writing groups before and after classes or on weekends when classes were not held. The program began an intentional effort to offer writing sessions to all enrolled students to meet this initial, organic effort.

The online writing sessions were part of a larger initiative to support EdD students in completing their dissertations and improving their writing. It was also a way to maintain and build a sense of community while students were socially distancing during the COVID-19 pandemic. Weekly writing sessions were first implemented as part of the EdD program in the summer of 2020 to develop early writing habits for students completing coursework and provide momentum for students in the dissertation in practice phases. The resources to design and launch the writing and data services are from the grant; however, they will be shifted to the program area over time. The writing sessions are facilitated by the EdD program's writing and data coach, a postdoctoral research scholar, who was hired to serve as a resource for students and support their progress toward completion. The writing and data coach, Laura Maldonado, participated in online writing sessions led by Jordan Dolfi, which were offered through a national research fellowship program in May 2020. These sessions served as the model for the writing sessions in the EdD program.

\section{Writing Session Development}

The structure of the writing sessions was adopted from the model consisting of multiple weekly offerings of two-hour writing blocks open to all program participants without prior registration required. As the EdD program consists primarily of full-time working professionals, students were surveyed to better understand accessible times for the writing session offerings. Based on feedback, four sessions (two morning and two evening) were offered each week, with each session running two hours in length. The groups met synchronously on three weekdays and every Saturday through the Zoom video conferencing platform. Saturday sessions were offered as students were used to taking coursework in the executive format schedule. All students currently enrolled in the EdD program, including both students taking courses as well as those working solely on their dissertations, were invited to participate in the writing sessions. Participation was voluntary. To remove potential barriers, registration was not required to attend. Rather, all current EdD students were emailed the access information and invited to drop in to any or all sessions as they were available.

The primary purpose of the offering was for students to have dedicated time blocked on their calendars to work on writing-related projects for their courses or dissertation, and the secondary purpose was to provide space for students to interact once they lost their regular in-person interaction during and between classes. Sessions were structured using the Pomodoro Technique, a time management system to structure writing time (Cirillo, 2018). Time blocks were varied within the two-hour sessions to help students learn how much they could accomplish within a timeframe. Students were given the option to pick their time block preferences if only one or two students participated in the writing session. Writing session participants were encouraged, but not required, to keep their webcams on while writing to provide a sense of togetherness and support as well as to support the accountability of spending the writing session time focused on the writing project. The identities of participants were not reported to the program faculty or committee members.

The program's writing and data coach developed a writing, research, or productivity tip each week to share during the first five minutes of the session. Additionally, the coach made the weekly fiveminute tutorials available to all current EdD students, whether or not they participated in the writing sessions, by recording the segment and emailing it once per week. EdD students could listen to the recording if they missed the writing session or wanted to hear it again. The email also provided a reminder to all students of the weekly writing session times.

\section{Writing Session Delivery}

The sessions encouraged students to focus on tasks related to writing rather than having a discussion about writing. Writing is a broad term used in this program to encompass any of the following tasks: brainstorming, outlining, reading, revising, editing, and writing. Similarly, the writing sessions were not intended to be "office hours" for writing support. To that end, writing sessions were not led by program faculty, but by a postdoctoral scholar serving the program. This intentional decision was made to reinforce the purpose of the writing sessions being to offer protected writing time and space. Students could ask questions through the chat feature but were instructed to schedule an individual meeting if questions were more in-depth in nature.

A sample structure of a writing session is provided in Table 1. The facilitator began each writing session by introducing a writing, research, or productivity tip in the first five minutes. Then students were instructed to prepare for the session by logging into citation management tools, cloud storage files, computer files, and library websites. Students were asked to set a goal or intention for the session and write it in the chat feature. The facilitator then started the writing sessions. The writing sessions varied from 25 -minute to $50-$ minute blocks within the two-hour session each week, which helped students think about what tasks they could accomplish in a specified number of minutes. The facilitator kept track of time and notified students when it was time to take 5-10 minute breaks. Students were encouraged to move around and rehydrate during the breaks. At the conclusion of the writing session, students were asked to make a note about where they were at in their writing and write one or two 
step items to accomplish for their next writing session. The structured writing time blocks were intended to model for students how they could set up successful independent writing sessions.

\begin{tabular}{ll}
\hline $\begin{array}{l}\text { Time Duration } \\
(2 \text { hours })\end{array}$ & Activity \\
\hline 5 minutes & $\begin{array}{l}\text { Introduce the tip of the week } \\
\text { Prep: Prepare for the session and set a goal/intention for } \\
\text { the session }\end{array}$ \\
& Write \\
45 minutes & Break: Encourage students to move around and rehydrate \\
10 minutes & Write \\
45 minutes & Wrap-Up: Tell students to make a note for where they are in \\
10 minutes & their writing project \\
\hline
\end{tabular}

Table 1. Sample Structure of a Writing Session

\section{DATA SOURCES AND COLLECTION}

The data sources utilized in this article included attendance records, an evaluation questionnaire, and a journal. The number of EdD students in attendance and their doctoral stage was kept by the writing session facilitator throughout the summer. Twenty-six EdD students from five cohorts participated in the writing sessions in the summer of 2020. There was a range of 2 to 13 participants in each writing session. Students were in various stages of the doctoral process: coursework, proposals, and the dissertation in practice.

An evaluation questionnaire consisting of nine questions was emailed after nine weeks of writing session offerings to gather quantitative and qualitative feedback from participating students (see Appendix). The questionnaire included five questions with a Likert scale (strongly disagree to strongly agree), three open-ended questions, and one question indicating cohort group selection. The questionnaire was voluntary, and responses were kept confidential. Evaluation questionnaire responses were received from 10 of the 26 $(38 \%)$ summer writing session participants. Finally, the facilitator also wrote in a journal to capture observations and reflections after leading each session. Frequencies and percentages were used to analyze the quantitative feedback. Data from the open-ended questions and the journal were coded and analyzed using a thematic approach.

\section{Student Perceptions}

Ninety percent of questionnaire respondents $(n=9)$ either strongly agreed or agreed they progressed with their writing goals as a result of the sessions. All students either strongly agreed or agreed the tip of the week identified resources for students to explore. Seventy percent of respondents $(n=7)$ agreed they were able to determine the length for writing tasks. Students also became more aware of the dissertation process with $60 \%(n=6)$ strongly agreeing and $30 \%(n=3)$ agreeing. Not all feedback was positive. Only $30 \%$ of participants $(n=3)$ agreed they had expanded their network of peers in the EdD program. However, the respondents responded positively to the open-ended question on the writing sessions providing a sense of community with their peers, as discussed in the next section.

Of 10 questionnaire respondents, nine completed the qualitative section, and $100 \%$ of responses received reflected a positive response to the question, "Would you recommend writing session participation to your EdD peers? Why or why not?" Participants wrote the following comments to explain:

"Yes, the accountability is important. It was good to look forward to an appointment that I did not want to miss so that I would focus on the tasks." (student 5)

"Yes, for the accountability, but also for the discipline of a set writing time," (student 6)

"Yes; during this time where there are so many competing demands, having time set aside is necessary." (student 9)

These responses suggest the ongoing schedule blocking and dedicated writing time on their calendars is of benefit to participants. Additionally, students reflected that the writing sessions provided a sense of community and provided the following examples:

"Yes! I appreciate having others present while writing because it makes the process less isolating and I feel more supported." (student 2)

"Yes! I've already mentioned it to a few folks in our cohort. It is great to have the devoted time to just work on writing tasks or coursework, knowing others are there to do the same and help me stay accountable." (student 7)

As discussed above, despite the disagreement that the writing sessions expanded participants' network of peers, qualitative responses indicated an impact on the sense of community in the program during the shift to online classes due to the pandemic.

When asked, "What do you see as the strengths of the writing sessions?", five of eight respondents reflected the benefit of dedicated writing time, with comments such as "structured time to focus with added support" (student 10) and "A specific time set aside to write" (student 9). Further, one respondent (student 2) referenced the benefit of the weekly tips and dissertation guidance: "The tips have been very helpful, as has the dedicated time spent on dissertation matters."

Gathering information through the questionnaire about program improvement was important as this was the first time the EdD program offered weekly online writing sessions. While most of the feedback was positive, students suggested several ideas for the future:

"It would be nice to have an online (accountability) journal to document goals for the next session..." (student 8)

"It would be great if there were sessions where we could share with one another about our dissertation, especially for those who are done with coursework" (student 9)

"Possibly show video clips or 'screen share' tips..." (student 4)

While feedback is in a preliminary and evaluative stage, the student perspective and voice has been both encouraging for this new program offering and thought provoking regarding improvements that could further enhance the sessions.

\section{LESSONS LEARNED}

The lessons learned presented in this section are based on evaluation information and the facilitator's reflection journal. Sharing the lessons learned during the design and implementation of these writing sessions could benefit other CPED programs that desire to provide students support by incorporating online writing sessions. 
With the rapid shift online, the program was not sure what to expect when the writing sessions began, especially given the uncertainty during the COVID-19 pandemic. However, the student feedback was encouraging, and revisions have already been made to the sessions based on feedback regarding time blocks, tips of the week, and expectations. The EdD program plans to offer writing sessions over the next year and continue to gather additional data. Insights from lessons learned relate to creating a space for students to write uninterrupted, communicating expectations, varying time blocks, brainstorming tips of the week, and maintaining community and social support.

\section{Creating a Space}

Perry and Abruzzo (2020) asserted the importance of EdD student investment in their successful progression. The writing sessions provided a space for the students to work on their dissertations that is often lacking once coursework is completed, supporting students' continued investment in their progression to degree.

Even though students start the dissertation process early in the program, the transition to the dissertation was often described as isolating as students' progress at varying rates after cohort coursework completion. Several students from earlier cohorts told the facilitator the writing sessions re-energized them to write as they had struggled to write since finishing coursework, a situation common among doctoral students (Russell-Pinson \& Harris, 2017). This is similar to what other online educational students have experienced in their doctoral programs (Rockinson-Szapkiw et al., 2016). This re-energization illustrates a renewed investment in doctoral research and progression to degree.

The writing sessions also provided students a space to interact outside of class time as well as to engage with the writing and data coach. Further, the sessions offered support for student progression without additional investment from faculty, allowing faculty to focus more on the content and dissemination to the field. This space also supports challenges administrators face to manage resources to support programs. Since the dissertation can often be a bottleneck in doctoral programs and require a significant amount of faculty resources, this model provides resources and could decrease students' time to completion (Page, 2020). Additionally, program faculty have recognized the quality of the writing has also improved.

\section{Communicating Expectations}

Deciding on the purpose and delivery surrounding the writing sessions at the beginning of the semester is important. Students participated in the sessions with different expectations about how sessions or writing groups should run. The writing sessions described in this article focused on dedicated time for writing. CPED EdD programs could consider incorporating training components, peer review, or brainstorming exercises. In the future, the facilitator will spend more time explaining the delivery of the writing sessions in a brief orientation session before writing begins. Students asked a variety of questions in the first few weeks of the semester (e.g., Is there a dress code? Do I have to keep my camera on? Can I ask questions in the chat feature? Is it okay to read literature and take notes instead of writing?). Providing a handout of answers to frequently asked questions or recording these questions and answers are other alternatives.
Deciding how much time to devote to student questions during the writing sessions is another area to consider. Students may ask different questions depending on who is facilitating. For example, students may ask questions about coursework assignments from a facilitator who is also their instructor. Students may also ask individual questions to a facilitator serving as their dissertation chair or on their committee. Facilitators will need to determine what questions to answer during the sessions and what questions need to be directed toward individual appointments and office hours. This decision may depend on the purpose and rationale of the writing sessions developed by the CPED EdD program.

\section{Varying Time Blocks}

Varying time blocks helps students learn how much they can accomplish within a timeframe. Students were given the option to pick their time block preferences if only one or two students participated in the writing session. The facilitator observed students selected longer time blocks over shorter time blocks (e.g., 45 minutes versus 25 minutes) when given this option at the beginning of the session. The EdD program offered writing sessions in 2-hour blocks, but programs could offer sessions of varying lengths. Programs considering incorporation of online, synchronous writing sessions should invest in learning about the Pomodoro Technique of structured work blocks and breaks (Cirillo, 2018) and determine the best time frame for the needs of their students. Students in the program who were unable to attend the sessions due to other responsibilities suggested the sessions be recorded and shared so they could play the recording and follow the writing blocks and breaks on their own schedule.

\section{Brainstorming Tips of the Week}

Initially, the facilitator brainstormed a new tip each week to share at the writing sessions. This took more time than anticipated to develop a tip that could be explained in less than five minutes. Now tips are based on suggestions submitted through an anonymous online form. The student questions posed in writing sessions can be used for future tips as they may determine where students may need additional assistance. This saves content development time for the facilitator and better addresses student inquiries. The tips also highlight ideas about services or programs available to EdD students. Audio recordings of the tips are saved in a shared folder accessible by all EdD students. The recordings serve additional purposes in that the recordings can be shared with students posing questions in classes or during meetings about dissertation writing. Less content may need to be developed after the first few months or year of creation.

\section{Building Community and Social Support}

The writing sessions provided an opportunity for the facilitator and students to engage with peers from several cohorts. Given the program shift to online delivery due to the COVID-19 pandemic, students were no longer able to see each other in person. The sessions provided virtual spaces to write among a community instead of writing by themselves (Lassig et al., 2013; Lee \& Boud, 2003; Murphy et al., 2014). In addition to benefiting the students, the writing sessions provided an avenue to support the workload of faculty while still highly engaging the doctoral students with more contact points. 
Although only $30 \%$ of participants agreed they had expanded their network of peers in the EdD program, this could be because students already knew each other. The facilitator observed many students knew each other's names and were engaged in conversation before the first session officially started. However, other students commented they had never met each other before participating in the writing sessions. This varied from session to session depending on who was in attendance. EdD programs could offer some special writing sessions before other program events or gatherings to encourage and attract different attendees. Students from several cohorts were able to meet and interact with each other that would not have been formed without the writing sessions.

\section{CONSIDERATIONS FOR THE FUTURE}

Writing sessions can be adapted for online, hybrid, and face-toface EdD programs. For CPED programs deciding whether to start writing sessions, consider the following questions:

\section{Who would be available to lead the writing sessions?}

Institutions may not be as fortunate to employ a postdoctoral scholar to support their EdD program; however, the writing sessions could be run by another program staff member, graduate assistant, or doctoral student. Students may be participating in self-managed cohort groups already and willing to host sessions with a larger number of EdD peers. There could be one facilitator designated to lead the sessions or the responsibility could be rotated among several session participants. Alternatively, the sessions could be run by a faculty member, but expectations should be made clear in advance about the purpose of the sessions. Faculty members should be appropriately compensated or recognized for this workload. The sessions could allow the faculty member to spend the session working independently on their own projects.

\section{Should the sessions be offered through online, hybrid, or face-to-face delivery?}

Students and facilitators can participate in online sessions anywhere with an internet connection, which removes a substantial barrier for student participation as well as providing flexibility for facilitators. Additionally, online sessions can be accessed by students enrolled in online, hybrid, and face-to-face classes. Physical space will need to be reserved for face-to-face sessions, which could be integrated in several ways through CPED programs. Hosting a writing session on campus when students return to face-to-face instruction will allow students to reconnect or meet each other for the first time. Sessions could then be offered before or after scheduled classes or during in-residence weeks. It is expected face-to-face sessions would increase the sense of community from participation but the extra time to travel to and from campus could present a barrier if not scheduled in conjunction with class or program times.

\section{What is the purpose or rationale of the sessions?}

The purpose of the sessions for the EdD program in reference was threefold: to support students' consistent progression to completion, to offer a sense of community for a typically face-to-face program during the pandemic, and to increase the interaction between students and the newly hired data and writing coach. CPED programs need to consider the specific needs of the program, faculty, and students and align the design of writing sessions with those needs.

\section{How can facilitators ensure the time is spent on writing and not answering students' questions or reviewing work?}

If the purpose of your program's writing sessions is to provide space and blocked time for writing, facilitators should be strict with the time blocks and encourage students to schedule meetings or conferences outside of the dedicated writing time. Other CPED programs may find building in more time for questions will be beneficial during the writing sessions.

Students indicated the writing sessions offered benefits beyond making writing progress in the dissertation, such as a sense of community and social support. The program plans to continue to offer writing sessions over the next year and gather additional data. Implementing or adapting program offering requires time and energy, but this could be an ideal time to offer online writing sessions to students enrolled in EdD programs, especially since the pandemic will continue into the coming months.

\section{ACKNOWLEDGEMENTS}

We would like to express our appreciation for the faculty who supported the launch of this initiative and the EdD students who participated in the writing sessions. It has been an inspiration to write with them on a weekly basis.

\section{REFERENCES}

Aitchison, C. (2009). Writing groups for doctoral education. Studies in Higher Education, 34(8), 905-916. https://doi.org/10.1080/03075070902785580

Aitchison, C. (2010). Learning together to publish: Writing group pedagogies for doctoral publishing. In C. Aitchison, B. Kamler, \& A. Lee (Eds.). Publishing pedagogies for the doctorate and beyond (pp. 83-100). https://is.muni.cz/el/sci/jaro2011/ZD500/um/39424704/Publishing_Pedag ogies_for_the_Doctorate_and_Beyond.pdf

Aitchison, C., \& Lee, A. (2006). Research writing: Problems and pedagogies Teaching in Higher Education, 11(3), 265-278. https://doi.org/10.1080/13562510600680574

Bartlett, J. E., Jr., Bartlett, M. E., Dolfi, J. J., Jaeger, A. J., \& Chapman, D. D. (2018). Redesigning the education doctorate for community college leaders: Generation, transformation, and use of professional knowledge and practice. Impacting Education: Journal on Transforming Professional Practice, 3(2), 59-67. https://doi.org/10.5195/ie.2018.80

Capello, S. (2020). Leveraging PhD students to support EdD dissertation writing. Impacting Education: Journal on Transforming Professional Practice, 5(3), 8-13. https://doi.org/10.5195/ie.2020.110

Carnegie Project on the Education Doctorate [CPED]. (n.d.) The CPED framework. Retrieved January 15, 2021, from https://www.cpedinitiative.org/the-framework

Cirillo, F. (2018). The Pomodoro Technique. Currency.

Colwill, D. A. (2012). Educating the scholar practitioner in organization development. Information Age Publishing.

D'Andrea, L. M. (2002). Obstacles to completion of the doctoral degree in colleges of education: The professors' perspective. Educational Research Quarterly, 25(3), 42-58.

Ferguson, T. (2009). The 'write' skills and more: A thesis writing group for doctoral students. Journal of Geography in Higher Education, 33(2), 285297. https://doi.org/10.1080/03098260902734968 
Inouye, K. \& McAlpine, L. (2019). Developing academic identity: A review of the literature on doctoral writing and feedback. International Journal of Doctoral Studies, 14(2019), 1-31. https://doi.org/10.28945/4168

Lassig, C. J., Dillon, L. H., \& Diezmann, C. M. (2013). Student or scholar? Transforming identities through a research writing group. Studies in Continuing Education, 35(3), 299-314. https://doi.org/10.1080/0158037x.2012.746226

Lee, A., \& Boud, D. (2003). Writing groups, change, and academic identity: Research development as local practice. Studies in Higher Education 28(2), 187-200. https://doi.org/10.1080/0307507032000058109

Lim, J., Covrig, D., Freed, S., De Oliveira, B., Ongo, M., \& Newman, I. (2019). Strategies to assist distance doctoral students in completing their dissertations. The International Review of Research in Open and Distributed Learning, 20(5), 192-210. https://doi.org/10.19173/irrodl.v20i5.4532

Maher, D., Fallucca, A., \& Mulhern Halasz, H. (2013). Write on! Through to the Ph.D.: Using writing groups to facilitate doctoral degree progress. Studies in Continuing Education, 35(2), 193-208. https://doi.org/10.1080/0158037X.2012.736381

McAlpine, L., \& Asghar, A. (2010). Enhancing academic climate: Doctoral students as their own developers. International Journal for Academic Development, 15(2), 167-178 https://doi.org/10.1080/13601441003738392

McPherson, C., Punch, S. \& Graham, E. (2018). Postgraduate transitions from masters to doctoral study: Managing independence, emotion, and support. Stirling International Journal of Postgraduate Research SPARK, 4(2018), 1-24. https://spark.stir.ac.uk/

Muirhead, B., \& Blum, K. D. (2006). Advising online dissertation students. Journal of Educational Technology \& Society, 9(1), 1-8. https://pdfs.semanticscholar.org/3a12/6b8596c4841cf2b54bfbcb2158032 3a9c36e.pdf

Murphy, S., McGlynn-Stewart, M., \& Ghafouri, F. (2014). Constructing our identities through a writing support group: Bridging from doctoral students to teacher education researchers. Studying Teacher Education, 10(3), 239-254. https://doi.org/10.1080/17425964.2014.949656

Okahana, H., \& Zhou, E. (2019, October). Graduate enrollment and degrees: 2008 to 2018. Council of Graduate Schools https://cgsnet.org/ckfinder/userfiles/files/CGS_GED18_Report_web.pdf

Page, C. (2020). Influences on doctor of education students who have completed all program requirements but dissertation (Publication No. 2458039647) [Doctoral dissertation, University of the Pacific]. ProQuest Dissertations and Theses Global.

Perry, J. A., \& Abruzzo, E. (2020). Preparing the scholarly practitioner: The importance of socialization in CPED-influenced EdD programs. In J. C Weidman, \& L. DeAngelo (Eds.) Socialization in higher education and the early career (pp. 129-146). https://doi.org/10.1007/978-3-030-33350-8_8

Rockinson-Szapkiw, A. J., Spaulding, L. S., \& Spaulding, M. T. (2016). Identifying significant integration and institutional factors that predict online doctoral persistence. The Internet \& Higher Education, 31, 101 112. https://doi.org/10.1016/j.iheduc.2016.07.003

Russell-Pinson, L., \& Harris, M. L. (2017). Anguish and anxiety, stress and strain: Attending to writers' stress in the dissertation process. Journal of Second Language Writing, 43, 63-71. https://doi.org/10.1016/j.jslw.2017.11.005

Wegener, C., Meier, N., \& Ingerslev, K. (2016). Borrowing brainpowersharing insecurities. Lessons learned from a doctoral peer writing group. Studies in Higher Education, 41(6), 1092-1105 https://doi.org/10.1080/03075079.2014.966671

Weidman, J. C., Twale, D. J., \& Stein, E. L. (2001). Socialization of graduate and professional students in higher education: A perilous passage? (ASHE-ERIC Higher Education Report, Vol. 28, No. 3). https://files.eric.ed.gov/fulltext/ED457710.pdf

\section{APPENDIX}

\section{Writing Session Questionnaire}

Q1 - As a result of the writing sessions, I progressed with my writing goals.

Strongly agree
Agree

Neither agree nor disagree

Disagree

Strongly disagree

Q2 - As a result of the writing sessions, I am able to determine time length for writing tasks.

Strongly agree

Agree

Neither agree nor disagree

Disagree

Strongly disagree

Q3 - As a result of the writing sessions, I increased my awareness of the dissertation process.

Strongly agree

Agree

Neither agree nor disagree

Disagree

Strongly disagree

Q4 - As a result of the writing sessions, I expanded my network of peers in the EdD program.

Strongly agree

Agree

Neither agree nor disagree

Disagree

Strongly disagree

Q5 - The tip of the week discussed at the writing sessions identified resources for me to explore.

Strongly agree

Agree

Neither agree nor disagree

Disagree

Strongly disagree

Q6 - What do you see as the strengths of the writing sessions?

Open Text Response Box

Q7 - What ideas, if any, can you offer for how to improve the writing sessions?

\section{Open Text Response Box}

Q8 - Would you recommend writing session participation to your EdD peers? Why or why not?

Open Text Response Box 
Q9 - Please select your cohort group.

Metropolitan Area 2016

Metropolitan Area 2017

Metropolitan Area 2018

Metropolitan Area 2019

Metropolitan Area 2020 